\title{
Experimental determination of change in the liquid layer thickness on the heated surface by confocal sensor
}

\author{
Dmitry Feoktistov ${ }^{1, *}$, Sergey Misyura ${ }^{1}$, Anastasia Islamova ${ }^{2}$, and Kseniya Batishcheva $^{2}$ \\ ${ }^{1}$ Kutateladze Institute of Thermophysics, Siberian Branch, Russian Academy of Sciences, \\ Novosibirsk, Russia \\ ${ }^{2}$ National Research Tomsk Polytechnic University, Tomsk, Russia
}

\begin{abstract}
Change of the distilled water layer thickness in time under the evaporation from stainless steel surface was studied experimentally. To register a change in the liquid layer thickness an experimental technique with the use of high-precision confocal method was developed. Change of the thickness of thin layers (less than $3 \mathrm{~mm}$ ) in time is found to have a linear nature. At decreasing the thickness up to $0.5 \mathrm{~mm}$, linear nature changes to the polynomial. It can be explained by the change in surface tension.
\end{abstract}

\section{Introduction}

It is necessary to provide heat removal from individual thermal loaded components and integrated modules [1-3] for reliable and accident-free operation of modern electronic equipment. The use of traditional cooling ways [4-8] based on the application of high heat flows of different heat transfer agents circulating through closed circuits are not always implemented technically and high priced. So to remove high heat flows around 1000 $\mathrm{W} / \mathrm{cm} 2$ [9-11], it is necessary to use enhanced heat exchange surfaces exceeding the area of heat source. In this case, one of the most effective ways of removing heat from the heatloaded elements is the use of cooling systems based on evaporation of thin liquid layers $[12,13]$. Compared to traditional systems, such systems use high energy potential of the phase transition $[8,9,12,14]$. Due to this effect, high intensity of heat removal during evaporation of thin liquid layers provides keeping of the required temperature mode of the element. There are many studies in this scientific field [15-19]. Scientific and technological progress contributes to the emergence of inexpensive high-precision equipment, such as confocal sensors. Their usage for study of thin liquid layer evaporation allow to clarify previously known physical mechanisms, and probably, to establish new ones.

The purpose of this work is to determine experimentally evaporation rates of thin liquid layers by using confocal sensor.

\section{Experimental apparatus}

* Corresponding author: fdv@tpu.ru 
Experimental studies have been conducted on the experimental setup (Fig.1). The main elements are registration system of the layer thickness (by using confocal sensor confocalDT 2451), temperature registration system (by using controller National Instruments and mini thermocouples Omega with a thermojunction of $80 \mu \mathrm{m}$ ), and test cell (Fig. 2).

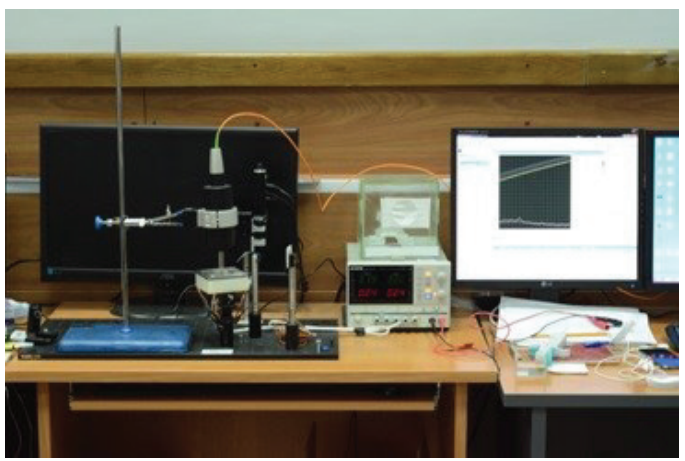

Fig. 1. Photographic image of the experimental setup.

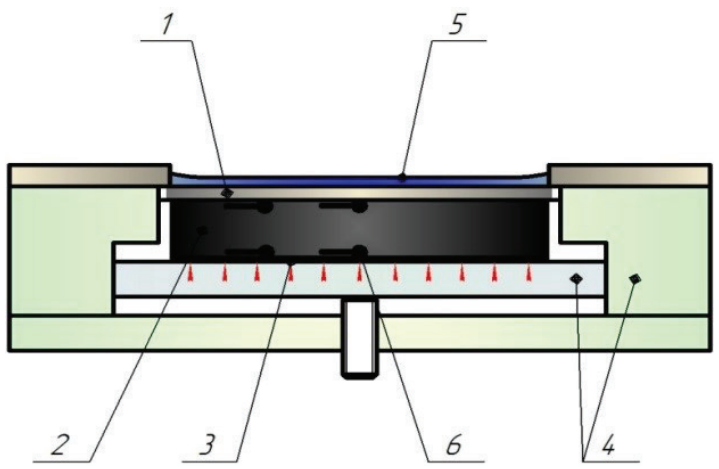

Fig. 2. The test cell: 1 - substrate; 2 - copper plate; 3 - piezoelectric element; 4 - case of the test cell made of thermal insulator; 5 - liquid layer; 6 - thermocouples.

A more detailed description of the test cell is given in [19].

Experiments were conducted at constant heat flow; the initial temperature corresponded to 80,90 and $100^{\circ} \mathrm{C}$. As a working liquid we chose the most common coolant, it is distilled water. Liquid from $1 \mathrm{~mm}$ to $3 \mathrm{~mm}$ thick was dosed on the substrate uniformly.

The layer thickness was recorded from the moment of placing the liquid on the substrate made of stainless steel to break of layer due to the phase deformation.

\section{Results and discussion}

According to results of conducted experiments the dependences of layer thickness from time were obtained (Fig.3). 


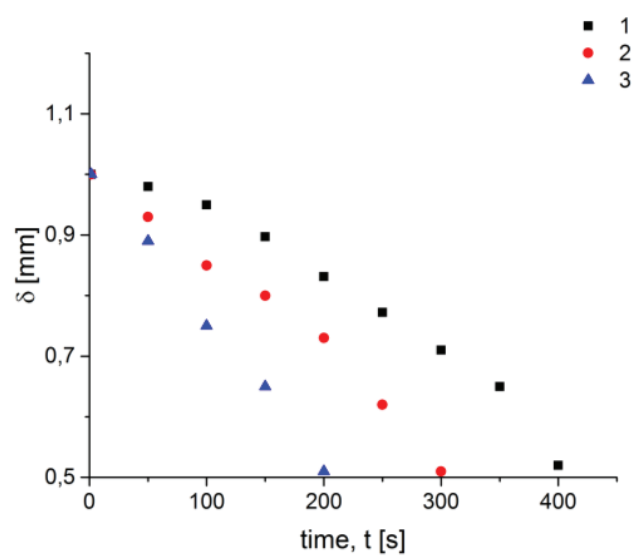

(a)

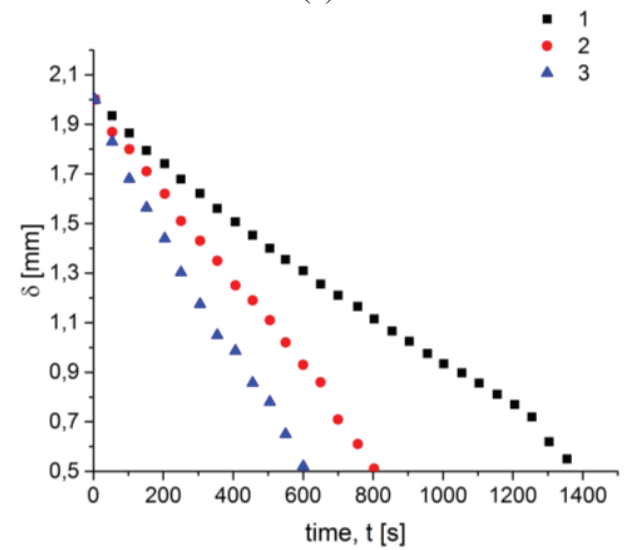

(c)

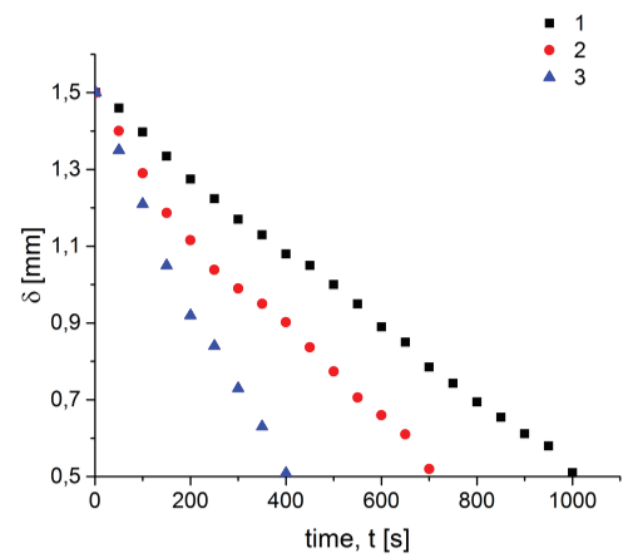

(b)

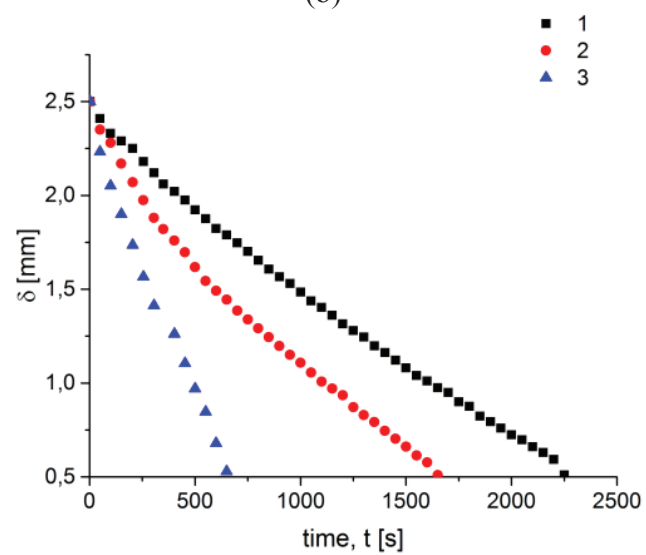

(d)

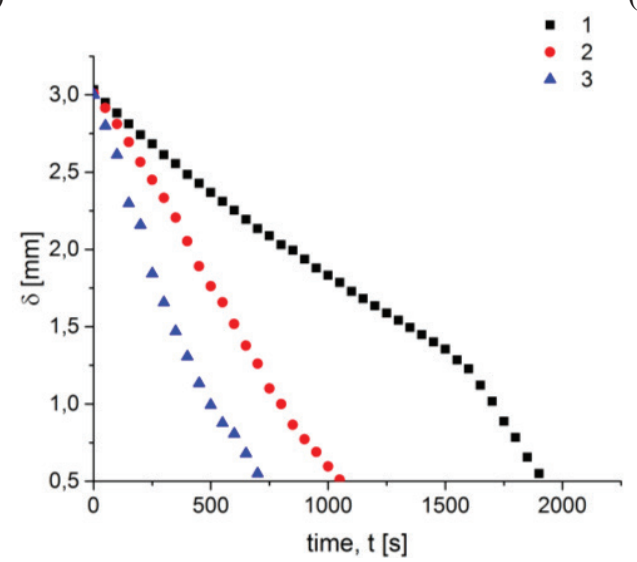

(e)

Fig. 3. Time dependences of distilled water layer thickness. The thickness of layer, mm: a) 1 ; b) 1.5 ; c) 2 ; d) 2.5 ; e) 3 . Substrate temperature, ${ }^{\circ} \mathrm{C}$ : 1) 80;2) 90; 3)100.

According to change of distilled water layer thickness it is found that the dependence has a linear nature. However, when the thickness decreases up to $0.5 \mathrm{~mm}$, linear nature changes to the polynomial. Probably, it can be explained by the following way. During decrease in the liquid thickness up to $0.5 \mathrm{~mm}$ there is a deformation of the interface. The flat shape of the surface transforms to wavy shape. It happens due to the surface tension. 
Interface energy on the solid/liquid boundary tends to compress the layer, i.e. the surface energy decreases due to decrease in surface area. Spreading is prevented by cohesive forces acting inside the liquid layer.

This work was carried out at the Kutateladze Institute of Thermo-physics SB RAS and financially supported by the Russian Science Foundation (project number 15-19-10025).

\section{References}

1. S. Misyura, Int. J. Therm. Sci., 92, 34 (2015)

2. V. Maksimov, T. Nagornova, I. Shestakov, EPJ Web of Conferences, 82 (2015)

3. V. Nakoryakov, S. Misyura, S. Elistratov, R. Dekhtyar, J. Eng. Thermophys., 23, 257 (2014)

4. G. Kuznetsov, A. Zakharevich, N. Bel'kov, Chemical and Petroleum Engineering, 50, $1(2014)$

5. A. Zakharevich, N. Bel'kov, EPJ Web of Conferences, 76 (2014)

6. V. Maksimov, T. Nagornova, O. Stepanova, MATEC Web of Conferences, 23 (2015)

7. V. Lebedev, V. Lemanov, S. Misyura, V. Terekhov, Fluid Dynamics, 28, 624 (1993)

8. D. Zaitsev, D. Rodionov, O. Kabov, Tech. Phys. Lett., 35, 680 (2009)

9. D. Zaitsev, D. Kirichenko, O. Kabov, Tech. Phys. Lett., 41, 551 (2015)

10. D. Zaitsev, M. Aviles, H. Auracher, O. Kabov, Microgravity Sci. Tec., 19, 71 (2007)

11. D. Glushkov, J. Legros, P. Strizhak, A. Zakharevich, Fuel, 175, 105 (2016)

12. Y. Lyulin, D. Feoktistov, I. Afanas'ev, E. Chachilo, O. Kabov, G. Kuznetsov, Tech. Phys. Lett., 41, 665 (2015)

13. E. Gatapova, R. Filipenko, Y. Lyulin, I. Graur, I. Marchuk, O.Kabov, Thermophys. Aeromech., 22, 701 (2015)

14. D. Glushkov, G. Kuznetsov, P. Strizhak, R. Volkov, Therm. Sci., 20, 131 (2016)

15. D. Glushkov, G. Kuznetsov, P. Strizhak, Math. Probl. Eng., 2014, 920480 (2014)

16. D. Feoktistov, E. Orlova, A. Islamova, MATEC Web of Conferences, 23, 01054 (2015)

17. D. Feoktistov, E. Orlova, A. Islamova, EPJ Web of Conferences, 110, 01018 (2016)

18. A. Semenov, D. Feoktistov, D. Zaitsev, G. Kuznetsov, O. Kabov, Thermophys. Aeromech., 22, 771 (2015)

19. K. Ponomarev, E. Orlova, D. Feoktistov, EPJ Web of Conferences, 110, 01060 (2016). 